\title{
Predictability in Equilibrium: The Price Dynamics of Real Estate Investment Trusts
}

\author{
Dennis R. Capozza* and Ryan D. Israelsen**
}

This research hypothesizes that, in markets where information costs, transaction costs and the economic impact of information can vary widely, we should expect predictability to vary systematically. We test this hypothesis with data on equity real estate investment trusts (REITs) from 1985 to 1992. We document that levels of predictability vary with firm characteristics like leverage, size and focus. Momentum is stronger for larger, more levered REITs. Reversion is faster for focused, levered REITs. The results are consistent with the hypothesis that, in equilibrium, securities, where information is either less costly to acquire or has less impact on fundamental value, should exhibit less predictability.

Is there an equilibrium level of predictability in asset markets? Numerous studies in real estate, equity and currency markets have documented significant momentum and reversion in these asset markets that vary over time and space and with the characteristics of the asset. Is this variation in predictability systematic? In this research we hypothesize that, in markets where information costs, transaction costs and the economic impact of information can vary widely, we should expect predictability to vary systematically. We test this hypothesis with data on equity real estate investment trusts (REITs) from 1985 to 1992 that include net asset values, a metric for fundamental value. We document that levels of predictability vary with firm characteristics like leverage, size and focus that proxy for information costs, transaction costs and economic impact. The data also allow us to compare the level of predictability in the relatively liquid equity markets to that of the less liquid property markets and to confirm that the more liquid market exhibits less predictability.

It has long been accepted that financial markets, in particular equity markets, are at least weak-form efficient so that excess returns cannot be earned by using investment strategies based on historical share prices or other public financial data. Efficiency, however, does not rule out predictability if information is costly to obtain. Theorists have modeled situations where predictability is

*Ross School of Business, University of Michigan, Ann Arbor, MI 48109 or capozza@ umich.edu.

** Ross School of Business, University of Michigan, Ann Arbor, MI 48109 or risraels@ umich.edu. 
consistent with rational expectations equilibrium or Bayesian Nash equilibrium (Brunnermeier 2001). ${ }^{1}$

Although information is a zero-marginal-cost good once produced, there are incentives to hide rather than share information for strategic reasons until positions have been secured in financial markets. The estimates that information traders use for the fundamental values of traded assets are not costlessly revealed in public data; but rather they must be produced at a cost by firms that specialize in collecting and analyzing the necessary information. These information producers may then trade profitably for their own accounts or sell the information to specialized trading firms like hedge funds. In equilibrium with free entry we should expect that the marginal producer/trader will break even but intra-marginal low-cost producers will continue to earn abnormal returns.

For example, an article on hedge funds in the Wall Street Journal provides evidence on the effects of equilibrating entry and exit from this industry:

Fat returns are becoming more elusive. In 2005, the average hedge fund returned $9.3 \%$, below the $11.4 \%$ average for the past decade, according to Hedge Fund Research Inc., a Chicago consultant. By comparison, the S\&P 500 index returned $7.7 \%$ last year. A record 848 hedge funds closed up shop in 2005, many of them hobbled by poor performance, according to Hedge Fund Research (Pulliam 2006).

Earlier research (Capozza, Hendershott and Mack 2004, CHM henceforth) on housing markets documented that housing prices have high degrees of both serial correlation and mean reversion, that the levels of correlation and reversion vary among metro areas and that the variation is at least in part attributable to the level of real income, population growth and construction costs. In frictionless markets predictable components of prices like correlation and reversion can be arbitraged and eliminated. While there may not be any completely frictionless markets, there are varying degrees of frictions like information costs and transaction costs among asset markets. Real estate markets are generally viewed as high-friction markets and equity markets as low friction.

Real estate properties are unique in trading both in illiquid property markets, on Main Street and in securitized portfolios of properties as real estate investment

\footnotetext{
${ }^{1}$ At least four situations can produce predictability in models that are consistent with the equilibrium: (1) asymmetric information and slow diffusion of the information (Hong and Stein 1999), (2) strategic behavior (Kyle 1985), (3) inventory effects arising from regular patterns of demand, HS henceforth (e.g., payday effects) and (4) liquidity and margin interactions: Brunnermeier (2006) outlines how volatility shocks can result in margin increases that eventually mean revert.
} 
trusts (REITs) on Wall Street, where liquidity can be enhanced relative to the underlying properties (Benveniste, Capozza and Seguin 2000). This duality enables natural laboratory experiments where we are able to control for numerous confounding factors by focusing on the behavior of the same or highly similar assets in two different markets.

Our research exploits this duality by applying the CHM (2004) framework for price dynamics to securitized real estate in REITs. We are able to compare both the degree of predictability and the determinants of predictability in these two markets. Our empirical tests focus on the interaction among the serial correlation and mean reversion coefficients and economic forces.

CHM (2004) translate standard empirical formulations for estimating serial correlation and mean reversion into a corresponding second-order difference equation. The properties of the difference equation determine the required parameter values that produce the four major dynamic structures: damped versus cyclical and convergent versus divergent or explosive. By first defining the mathematical structure implied by the empirical estimates, they are able to give rigorous definition to terms like "overreaction," "underreaction" and "bubble." Overreaction occurs when the correlation and reversion coefficient pairs assume values in the oscillatory region where the roots of the characteristic or complementary function of the difference equation are complex. Mathematically, a coefficient pair that lies in the divergent or explosive region is one way to define a bubble. This divergent behavior arises when the serial correlation exceeds one.

In this research we estimate the relevant correlation and reversion parameters using a unique panel data set for 75 equity REITs from 1985 to 1992. An important variable in the data set is the net asset value (NAV) of each REIT for each year. The NAVs are carefully constructed from the values of the properties held by each REIT using the procedure documented in Capozza and Lee (1995, 1996, CL henceforth). For each REIT property, the location and property type (e.g., office, retail, industrial or apartment) is identified and used to obtain an estimate of the current market value of the underlying properties. These values are then substituted for Generally Accepted Accounting Principles-depreciated property assets on a REIT's balance sheet to obtain the NAVs.

In studies of mean reversion one must ask what the values are that the assets revert toward. In most cases ${ }^{2}$ reversion is simply defined as price reversal at some horizon. A more meaningful economic basis for reversion is reversion to a

${ }^{2}$ For example, see De Bondt and Thaler (1985), Jegadeesh (1990), Jegadeesh and Titman (1995) and Lo and MacKinlay (1990). 
suitably defined fundamental value. If fundamental values can be obtained, more powerful tests of reversion become possible. Reversion can then be observed not only when prices reverse direction but any time prices converge to the fundamental value. By contrast, using price reversals to define reversion is fraught with both type I and type II errors, which are mitigated by having a metric for fundamental value. For example, if fundamentals improve at the same time that a stock is reverting down, we will not see a price reversal if the improving fundamentals exceed the reversion. In this study, we use the NAVs as our metric for fundamental value.

In the absence of conditioning on fundamental value, estimates of momentum will be biased because a relevant variable is being excluded. For example, consider an asset whose price and value are initially $\$ 20$. If the fundamental value increases to $\$ 30$ and the price does not adjust fully and immediately to this new level, the price must revert toward $\$ 30$ over time. This reversion to the new fundamental value will be misidentified as serial correlation if fundamental value and a reversion parameter are not included in the estimates.

The analytical framework of CHM (2004) is closely related to the story and analysis in HS (1999). In HS (1999) two types of boundedly rational traders interact in financial markets: "newswatchers," or information traders, and "momentum" traders. Information traders trade on new information. If information diffuses slowly to the risk-averse information traders, equity prices underreact to new information and revert slowly and predictably to the new fundamental values. The underreaction implies that momentum traders can profit by trend chasing because they are able to analyze price movements and infer future price movements from the price patterns caused by the slow diffusion of information. The presence of momentum traders whose forecasts are simple functions of past prices accelerates prices in the direction of fundamentals, "but this comes at the expense of creating an eventual overreaction to any news" (HS 1999). Notice that the actions of momentum traders directly impact the momentum or autocorrelation whereas those of the information traders determine the speed of reversion.

Our contributions are first to provide a direct comparison of predictability in the liquid and illiquid incarnations of real estate assets. Second, we provide additional evidence on serial correlation and mean reversion in equity markets using a unique panel data set with direct metrics for fundamental value that are normally not available and that enable more powerful statistical tests than in previous research. Third, and most importantly, we model and estimate equations relating the extent of serial correlation and mean reversion to possible determinants such as information costs, transaction costs and valuation precision. 
In the next section we review the CHM framework and the difference equation that characterizes the dynamic properties. The third section describes the panel data set we use for our estimates, and the fourth section discusses the empirical results. The fitted values for the coefficients indicate the wide variation in possible dynamics. The final section summarizes and concludes.

\section{Dynamics in the CHM Model}

The concept of mean reversion is the basic notion that, in the long run, markets converge toward equilibrium. In financial markets, long-run equilibrium implies that there are no arbitrage opportunities within the limits of transaction costs. An important characteristic of REITs is that if the shares are selling for less than the value of the underlying properties then a REIT can sell properties and distribute the cash to shareholders. In the converse case, a REIT can issue stock and buy more properties, thereby causing convergence of stock prices and the underlying properties. That is, the NAV we will use as a proxy for fundamental value is directly arbitragable, albeit at a substantial cost. ${ }^{3}$

In each time period, $t$, and for each REIT, we assume there is a long-run equilibrium value for the stock price that is determined by the value of the underlying property assets and other variables:

$P_{t}^{*}=p\left(V_{t}, X_{t}\right)$,

where $P^{*}$ is the equilibrium or fundamental value per share for the REIT, $\boldsymbol{V}_{t}$ is the NAV per share as defined above and $\boldsymbol{X}_{t}$ is a vector of other explanatory variables that influence the fundamental value.

Value changes in CHM (2004) are governed by reversion to the fundamental value and by serial correlation according to

$\Delta P_{t}=\alpha \Delta P_{t-1}+\beta\left(P_{t-1}^{*}-P_{t-1}\right)+\gamma \Delta P_{t}^{*}$,

where $\Delta$ is the difference operator. If we define $P_{t}$ to be the stock price at time $t$, then Equation (2) represents a dollar return formulation. Alternatively, we can define $P_{i}$ to be the $\log$ of the dividend-adjusted stock price to obtain the more

\footnotetext{
${ }^{3}$ An interesting question to ask is whether arbitrage will cause REIT equity prices to converge to the NAVs implied by Main Street property prices or the Main Street property prices to converge to the implied cap rates in the equity markets. Because the commercial real estate market is very large (worth trillions of dollars) relative to the amount of real estate securitized into REITs (less than $\$ 10$ billion of REIT equity in the sample time period), we expect that most of the impact of any arbitrage activity will be on REIT equity prices rather than on the underlying properties. Even today after 20 -fold growth of REIT equity, REITs remain a small percentage of the overall commercial property markets.
} 
common percentage return formulation. The first term on the right in Equation (2) is the serial correlation, or momentum term, where $\alpha$ is the serial correlation coefficient. The second term is an error correction or reversion term that provides reversion to the equilibrium value. $\beta(0<\beta<1)$ is the rate of reversion or adjustment to the equilibrium. The third term captures the contemporaneous adjustment to fundamentals. Partial adjustment implies that $0 \leq \gamma \leq 1$.

Equation (2) can be rewritten in difference equation form by substituting $P_{t}-$ $P_{t-1}$ for $\Delta P_{t}$.

$$
P_{t}-(1+\alpha-\beta) P_{t-1}+\alpha P_{t-2}=\gamma P_{t}^{*}+(\beta-\gamma) P_{t-1}^{*} \text {. }
$$

The solution is described by the pair of roots, $B_{1}, B_{2}$, given by

$$
B_{1}, B_{2}=\frac{(1+\alpha-\beta) \pm \sqrt{(1+\alpha-\beta)^{2}-4 \alpha}}{2},
$$

which arise from rewriting and solving the left-hand-side quadratic, $p^{2}-(1+\alpha-\beta) p+\alpha=0$.

\section{Oscillations}

When the roots are complex, that is, when

$(1+\alpha-\beta)^{2}<4 \alpha$,

oscillations or cycles will occur. Therefore, in $(\alpha, \beta)$ parameter space, when the $(\alpha, \beta)$ pairs satisfy Equation (7), prices will exhibit oscillatory behavior (overshooting). Otherwise, price changes will be damped (no overshooting).

Stability of equilibrium requires that the moduli of the roots, $B_{1}, B_{2}$, both be less than one. See CHM (2004) for more detail. With the restrictions from the economics of the problem, a necessary condition for convergence to equilibrium is that the absolute value of serial correlation, $\alpha$, is less than one.

$|\alpha|<1$.

Conditions (5) and (6) divide the parameter space into four regions. Figure 1 summarizes the analysis graphically in $(\alpha, \beta)$ parameter space. In the figure, the curve defined by Equation (5) separates cases without oscillations below the curve from parameter pairs with fluctuations above the curve.

The vertical line at $\alpha=1$ divides the parameter space into a divergent or explosive region to the right of the line and a convergent region to the left. When the autocorrelation coefficient is above unity, deviations from steady state are magnified over time and the path of values diverges from the long-run equilibrium. 
Figure 1 The dynamic behavior of the difference equation.

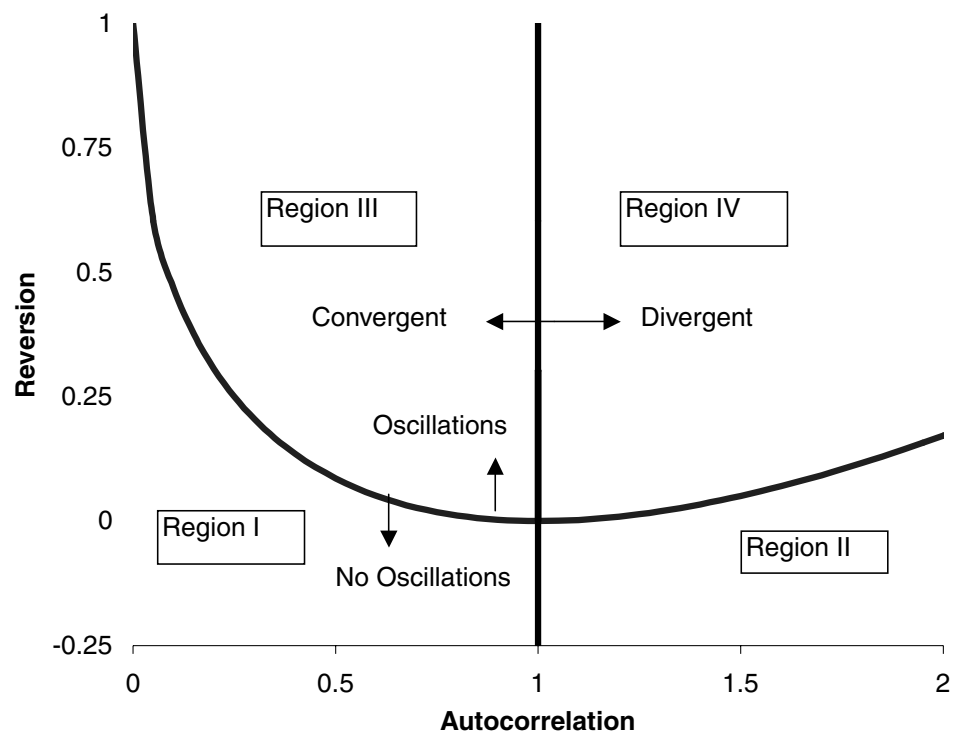

This graph illustrates the parameter values that generate the various dynamic patterns when equilibrium is shocked. Values of the autocorrelation coefficient greater than 1 result in divergent or explosive behavior. Parameter values that lie above the curved line result in oscillations or cycles (overshooting).

The two curves divide Figure 1 into four regions. Figure 2 summarizes the types of dynamic behavior that arise in each of the four regions in response to a ramp change in $P^{*}$. A subcase of region one occurs when serial correlation, $\alpha$, is negative. In this subcase, price converges without oscillations but in a twoperiod sawtooth-alternating pattern caused by the negative autocorrelation.

\section{The Data}

The database, introduced and described in detail in CL $(1995,1996)$ and subsequently used in Bradley, Capozza and Seguin (1998), Benveniste, Capozza and Seguin (2001) and Capozza and Seguin (1998, 1999, 2000, 2001a, 2001b), contains a subset of the REITs listed in NAREIT (National Association of Real Estate Investment Trusts) source books from 1985 to $1992 .{ }^{4}$ The database contains balance sheet and income statement information on 75 exchange-traded

\footnotetext{
${ }^{4}$ Many REIT observers conjecture that the newer REITs that went public after 1991 are different from the earlier generation of REITs in our sample. Recently the possibility of a regime shift for REITs has been tested over the 1971 to 2004 period by Kim, Leatham and Bessler (2006), who find that there is a statistically significant break point in the dynamics of REITs but that it is in 1980 not in 1992. Thus the statistical evidence suggests that our sample is likely to be representative of REIT behavior from 1980 forward.
} 

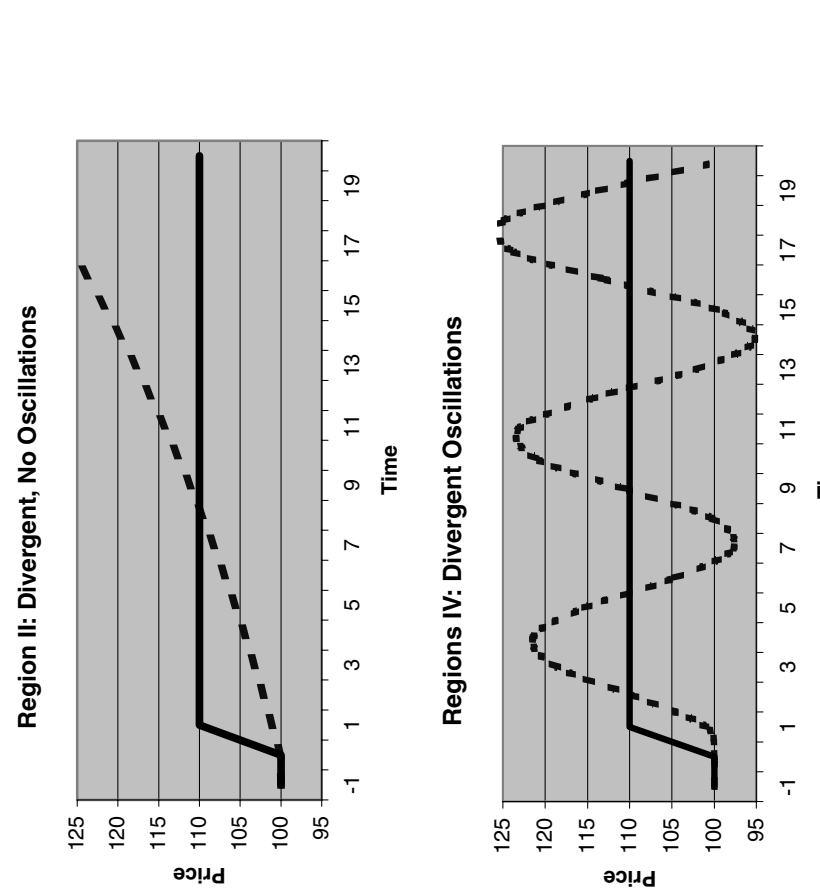

$\stackrel{0}{\Xi} \overline{0}$

$\exists$

品

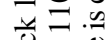

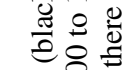

응응

층 छ

ป

当䒠

ํㅜㅇ

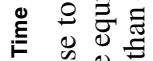

证

它

$\Xi$ 品

政

郭

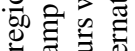

可 ठ⿹

든ㅇㅇ

过

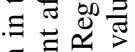

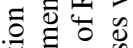

艺司

क्षे
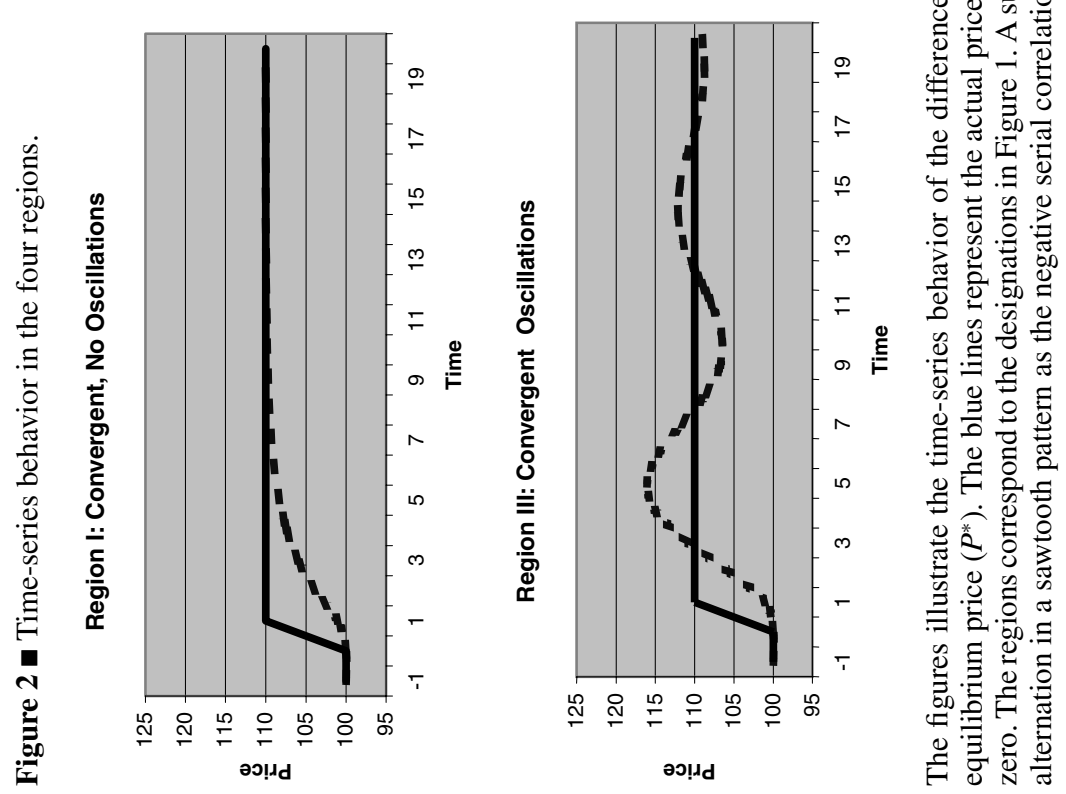
equity REITs. Retail, office, industrial and apartment REITs, where data on the underlying properties is available, are included. Mortgage, hotel, restaurant and health care REITs are excluded. Additional financial data for each of the 298 usable annual observations were manually extracted from $10-\mathrm{K}$ reports, annual reports and proxy statements.

A unique feature of the CL $(1995,1996)$ database is estimates of the NAVs of the properties held. To create the NAVs, CL assigned location- and propertytype-specific capitalization rates to each property and then calculated a REIT's aggregate capitalization rate as the weighted average of the real estate asset portfolio capitalization rates. Property assets were then calculated by dividing the REIT's total property cash flow by the weighted capitalization rate. Finally, NAVs were calculated by subtracting liabilities from estimated property assets plus other assets. Additional adjustments were made for joint ventures, differences between coupon rates and market yields on debt and also property turnover. ${ }^{5}$

It is important to note that the property-specific capitalization rates and hence property values are estimated using actual transaction data from the commercial property market. Thus, these values provide a meaningful anchor for a REIT's strategy when stock prices deviate from the underlying value of the properties. As indicated above, a REIT can sell (buy) stock and buy (sell) properties when stock prices deviate by more than a transaction-cost boundary from the NAVs. Thus we view NAVs as an excellent proxy for fundamental value.

It should also be noted that, because the CL procedure uses cap rates that are specific to the property type and to the location (metro area), these estimates of NAV control for much of the risk and growth opportunities associated with the assets underlying the REITs. The corporate-level growth opportunities, which are reflected in the stock prices, will arise primarily (but not solely) from the growth opportunities in the properties. Thus, when comparing stock prices to NAVs, most growth opportunities have been included in both the equity and property valuations.

\footnotetext{
5 The NAV estimates are not simple capitalizations of funds from operations conditional on an arbitrary capitalization rate, as is often and easily done by practitioners. Instead, the NAV estimates are carefully aggregated from prices, rents and capitalization rates specific to the property types and locations of the properties held by each REIT. To date, no one has duplicated or extended the data sample with data of similar academic quality.
} 
Table 1 @ Summary statistics.

\begin{tabular}{|c|c|c|c|c|}
\hline Variables & Mean & $\begin{array}{l}\text { Standard } \\
\text { Deviation }\end{array}$ & Minimum & Maximum \\
\hline $\begin{array}{l}\text { Market Capitalization } \\
\text { (Wall Street Market } \\
\text { Value of Equity) } \\
\text { (\$ Mil.) }\end{array}$ & 116.3 & 143.9 & 4.1 & $1,070.8$ \\
\hline $\begin{array}{l}\text { Net Asset Value (Main } \\
\text { Street Value of Equity) } \\
\text { (\$ Mil.) }\end{array}$ & 110.3 & 107.5 & 5.9 & 642.1 \\
\hline Tobin's $q$ ratio & 1.00 & 0.37 & .10 & 2.86 \\
\hline Dollar Volume (\$ Mil.) & 131.3 & 152.8 & 1.3 & 925.1 \\
\hline Leverage Ratio (\%) & 35.8 & 23.7 & 0.3 & 90.0 \\
\hline $\begin{array}{l}\text { Property Type } \\
\text { Herfindahl }(\%)\end{array}$ & 66.8 & 24.1 & 26.0 & 1.00 \\
\hline $\begin{array}{l}\text { Percentage Held by } \\
\text { Insiders }\end{array}$ & 7.3 & 10.0 & 0.0 & 42.0 \\
\hline
\end{tabular}

This table reports means, standard deviations and extreme values for a number of summary statistics calculated across our sample of 298 observations for 75 firms. Wall Street Value of equity is the market capitalization (size) of equity. Main Street Value of Equity is the real estate market value of assets as defined by Capozza and Lee (1995) minus the book value of liabilities. Tobin's $q$ ratio is the ratio of market equity (stock price times number of shares) to the market value of properties plus the book value of other assets minus book liabilities. Turnover is the annual dollar volume divided by the market capitalization. The leverage ratio is defined as total liabilities/(total liabilities + market value of the equity). The Herfindahl concentration measure is the sum of squared fractions of asset portfolios by property type and geographic regions, respectively.

Summary statistics for these Main Street-determined fundamental values and for Wall Street-determined market capitalization values are presented in the first two rows of Table 1. Both Wall Street and Main Street equity values average just over $\$ 100$ million and vary from essentially zero to $\$ 1$ billion ( $\$ 650$ million for Main Street replacement values).

In the empirical analysis that follows we will explore the interaction between the parameters of the difference equation and a variety of metrics for information costs, transaction costs and valuation precision. To control for the effects of relative liquidity, we follow the lead of both finance and real estate literatures and employ annual dollar trading value. ${ }^{6}$ Dollar volume varies from $\$ 1$ million

${ }^{6}$ See Peterson and Fialkowski (1994), in finance and Bhasin, Cole and Kiely (1997), Benveniste, Capozza and Seguin (2001) and Clayton and MacKinnon (2000) in real estate. 
to just under $\$ 1$ billion, with a mean of around $\$ 130$ million. The variation is also dramatic when expressed as a multiple of equity: the range is one-eighth through five-and-a-half.

We include a measure of the focus of the asset base: the Herfindahl index based on property type. The Property Type Herfindahl is computed as $\sum_{t=1}^{4} \int_{t=1}^{4} S_{t}^{2}$, where $S_{t}$ is the proportion of a firm's assets invested in each of four real estate types: office, warehouse, retail or apartment. This metric varies across almost their entire range.

The CL (1995, 1996) database contains measures of regulatory-defined insider ownership gleaned from the Spectrum database. The underlying source of such data is the collection of 13-D quarterly filings that insiders and institutions must file quarterly with the SEC. ${ }^{7}$ Holdings by insiders vary from $0 \%$ to $42 \%$ with a mean of $7 \%$.

\section{The Initial Estimates of the Base Model}

\section{Comparison of REITs to the CHM Housing Estimates 8}

We begin by comparing the results from estimating Equation (2) for REITs with the estimates in CHM (2004) for housing. ${ }^{9}$ With lower frictions in the equity markets we expect less predictability for REIT prices. The results are displayed in Table 2, Models 1-4. The first model displays the housing market estimates from CHM (2004). The second model uses actual REIT annual returns as the dependent variable, while the third and fourth use Roll (1984) returns that skip one month in the return calculation to mitigate the negative serial correlation induced by bid/ask bounce. Model 4 uses firm-level fixed effects as well as time fixed effects. ${ }^{10}$

\footnotetext{
7 See CL (1995) for details.

${ }^{8}$ In this research we use "predictability" in the traditional sense where future returns are not completely independent of the information set available today and focus on the size of the momentum and reversion coefficients. An alternative approach (e.g., Durnev et al. 2003) focuses on the fit of a market model and argues that a low $R^{2}$ signals more information-laden stock prices.

${ }^{9}$ It can be argued that a more relevant comparison would be between REITs and commercial property rather than residential property. However, similar results for commercial property are not available as yet. Residential property is the closest available proxy for commercial real estate. Relative to residential real estate, commercial real estate is characterized by larger transaction sizes and much less liquidity. Therefore, at least in these dimensions, we should anticipate even starker comparisons for commercial real estate.

${ }^{10}$ Many argue that REITs are more than a collection of properties and that specific managers and structures can add or detract from the value of the firm. REITs tended
} 
552 Capozza and Israelsen

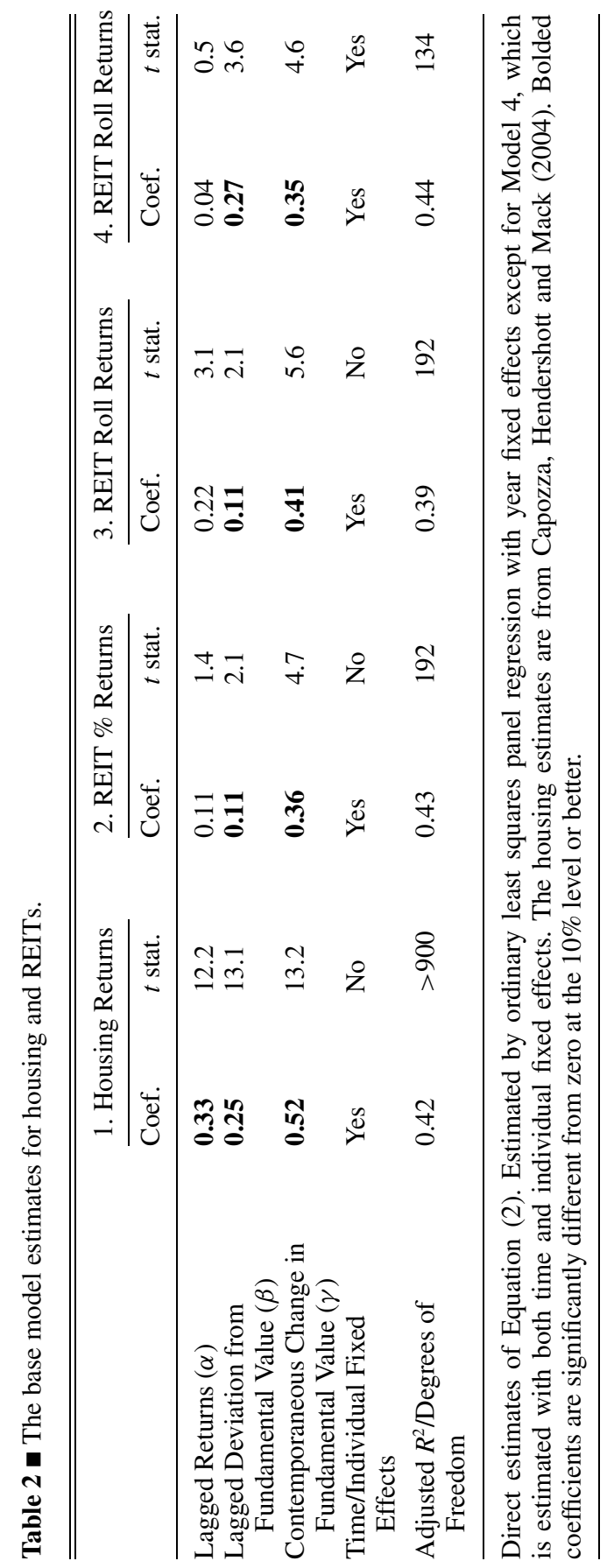


Both the correlation and reversion estimates, $\alpha$ and $\beta$, are typically smaller in the REIT sample than in the corresponding housing sample, that is, there is less predictability in the equity-REIT market than in the housing market as expected. $\alpha$, in particular, is not statistically significant in Model 2, the percent return version, and is about one third the size of the corresponding housing coefficient. Using Roll returns in Model 3 reduces the effects of bid/ask bounce (see below) and doubles the $\alpha$ estimate to a significant level. Adding firm-level fixed effect in Model 4, however, returns the $\alpha$ estimate to an insignificant level. These results are consistent with the hypothesis that REIT equity markets are subject to smaller transaction and information costs than housing markets.

The $\beta$ estimates for REITS are significant in all versions and similar in magnitude to those for housing. These results are consistent with slow diffusion of information in both the housing and REIT equity markets.

The coefficient for the contemporaneous change in fundamental value, $\gamma$, is similar in magnitude across the markets and is always highly significant. A significant $\gamma$, however, does not imply predictability unless contemporaneous changes in fundamentals are predictable.

Because the return data in Model 1 are based on yearly averages of price data, the $\alpha$ for housing is biased upward (Working 1960). On the other hand, the $\alpha$ for REITs is biased downward from the effects of bid-ask bounce (Roll 1986). To address this later bias we follow the standard practice of deleting a month from the data so that yearly returns are calculated from the end of January to the end of December instead of from end of December to end of December. The results appear as Models 3 and 4 in Table 2. The coefficient for $\alpha$ is significant and positive in Model 3 with only time fixed effects but becomes insignificant in Model 4 when individual fixed effects are included.

To summarize this section, we find strong evidence that REITs adjust to fundamentals contemporaneously. About 35-40\% of this effect occurs in the year of the change in fundamentals. Additional reversion toward fundamental value occurs in future years at a rate of $11-27 \%$ per year. Despite this predictable pattern of reversion, there is little evidence of continuance arising from trend following momentum traders in the final Model 4 with both time and individual fixed effects for this sample of REITs. This latter result contrasts with the evidence in Chui, Titman and Wei (2003, CTW henceforth) who do find significant

to be more passive in their investment strategies during our sample period than today. Nevertheless, we include firm-level fixed effects to address the concern that some REITs that add value to their properties might not converge to the strict calculated NAV. 
momentum in the pre-1990 period. The CTW (2003) sample, however, does not include a metric for fundamental value and uses a shorter holding period.

Arguably, REITs were an unattractive sector for momentum traders during this time period. REITs were small, weakly followed by analysts and thinly traded during this sample period. All these factors might make REITs unlikely targets for momentum traders.

In the next section we explore whether the degree of momentum and reversion ${ }^{11}$ is influenced by metrics for information costs, transaction costs and valuation precision.

\section{The Determinants of Equilibrium Correlation and Reversion}

Our goal in this section is to explore the causes of differences in the dynamic response of REIT equity prices to shocks. In the context of the model, these differences will appear as different estimates of $\alpha$ and $\beta$. Therefore, we rewrite Equation (2) as

$$
\begin{aligned}
\Delta P_{k t}= & \left(\sum_{i} \alpha_{i}\left(Y_{k i t}-\bar{Y}_{i}\right)\right) \Delta P_{k, t-1}+\left(\sum_{i} \beta_{i}\left(Y_{k i t}-\bar{Y}_{i}\right)\right)\left(P_{k, t-1}^{*}-P_{k, t-1}\right) \\
& +\gamma \Delta P_{k t}^{*},
\end{aligned}
$$

where $i$ indexes the variables, $k$ indexes REITs, the $Y_{i}$, which may include a subset of the $\boldsymbol{X}$ and a unit vector, are independent variables and $\bar{Y}_{i}$ represents the mean value of $Y_{i}$ in the sample. ${ }^{12}$

An important issue is the choice of the $Y_{i}$, which affects the predictability coefficients $\alpha$ and $\beta$. Many stories, both behavioral ${ }^{13}$ and rational ${ }^{14}$ are consistent with predictability. For example, all the estimates of $\gamma$ in Table 2 are much less

\footnotetext{
${ }^{11}$ It is worth noting that we have not assumed that one market is correct and the other wrong. Prices in both markets will interact to achieve efficient prices in both markets. However, because the private commercial real estate market is so much bigger (close to $\$ 1$ trillion) than the public equity market (less than $\$ 10$ billion) during the sample period, we should expect any arbitrage between the two to impact the smaller equity market more than the larger private market.

${ }^{12}$ In Equation ( $\left.2^{\prime}\right)$ we have assumed that $\gamma$ is not endogenous. Allowing for endogeneity affects the amplitude but not the frequency (CHM 2004).

${ }^{13}$ See Odean (1998), Barberis, Shleifer and Vishny (1998), Daniel, Hirshleifer and Subrahmanyam (1998) and Barberis and Huang (2001).

${ }^{14}$ See Conrad and Kaul (1998), Berk, Green and Naik (1999) and Johnson (2002).
} 
than one. This means that less than the full change in fundamentals is incorporated into the prices contemporaneously. If investors underreact to changes in fundamentals in one period, then prices must mean revert toward fundamental value in the future if equilibrium is ever to be attained. A behavioral explanation would emphasize psychological studies that document underreaction or overreaction to new information. ${ }^{15}$ Rational approaches, on the other hand, might focus on costly information that diffuses slowly (Heaton and Brav 2002, HS 1999).

Econometrically, if we believe Equation (2) is the correct model, then exclusion of one of the variables will bias the remaining coefficients, that is, the standard bias arising from exclusion of a relevant variable. For example, suppose only lagged price changes are included and mean reversion is excluded. If mean reversion is partial in each time period, that is, if $\beta$ is less than one, then successive price change realizations will tend to have the same sign as prices revert to fundamental value. The estimated statistical serial correlation, then, will be biased upward. Thus the serial correlation, or $\alpha$, as defined in Equation (2), is not identical to momentum as typically defined in the finance literature. Because metrics for a fundamental value are generally not available in studies of price predictability in financial markets, most estimates of momentum are biased upward.

Among the research on equity markets, the most closely related model to our Equation (2) is the work by HS (1999). In the HS world there are two types of boundedly rational stock traders, information traders, or newswatchers, and price traders. Information traders follow information events and conditionally reassess their estimate of the value of the equity based on the new information. Information, especially nonpublic information, is not impounded immediately into prices but diffuses slowly to the information traders. Information traders might include insiders who would clearly have access to accurate and timely information and value investors who have a comparative advantage at processing the new information. As the information diffuses, the stock price will tend to move in one direction over a period of time.

Price traders, on the other hand, follow the stock price movements but not the news. When they observe one-sided movements, that is, trends or momentum, they piggyback on the information traders and make trades that reinforce the trend. If returns are correlated, then price traders (technicians/momentum traders) can use price history to trade profitably provided they identify the trends early enough.

${ }^{15}$ See Bern (1965) and Tversky and Kahneman (1974). 
In Equation (2) or ( $\left.2^{\prime}\right)$, implicitly, the $\alpha$ arises from the actions of the price traders, while the $\beta$ emerges from the optimization of the information traders. Although both types of traders are constrained to specific types of information, they are nevertheless rational optimizers within the bounds of the constraints. We expect the following stylized facts to apply:

- Impact - Companies where the information event will have more impact will be preferred. For example, macroeconomic or industry events will be magnified for highly levered firms, making them more efficient trading vehicles.

- Precision-Companies and events with more precise information (higher signal-to-noise ratios) will be the preferred trading vehicles. Price traders should be more active in securities that have stronger trends relative to their volatility. Information traders should be more active among companies where financials are more transparent, thus making it easier to assess the impact of any new information.

- Costs-Because revenue from trading must more than cover transaction costs, securities with lower transaction costs will be preferred.

\section{Economic Impact}

Any given unit of information will have more impact on asset prices when the security is leveraged to the information. For REITs, both operating and financial leverage will affect economic impact. However, we expect financial leverage to be the more important because financial leverage varies widely (see Table 1) whereas operating leverage should be similar among firms in the same industry.

\section{Information and Transaction Costs}

Most of the research on predictability has focused on the role of information and transaction costs. First, consider the role of information dissemination. Real estate markets are a natural place to argue that relevant information will diffuse slowly. In real estate markets information costs are high, transactions are infrequent and the product is highly heterogeneous. As a result, participants have difficulty assessing the current value of properties and may have to use sales distant in time or location for setting reservation prices (Quan and Quigley 1991). Markets with a higher number of transactions have lower information costs; thus, prices should adjust more quickly to their long-run equilibrium value, that is, mean reversion should be greater. Clapp, Dolde and Tirtiroglu (1995) argue that information costs will be lower the greater the number of transactions per unit area. 
In contrast to the underlying properties, real estate stocks are traded frequently, which should improve the flow of information. On the other hand, REITs are portfolios of the underlying properties, which obscure the property-level information Hong, Lim and Stein (2000) test the implication of HS (1999) that stocks for which information travels slowly have more momentum. They find that the profitability of momentum strategies declines with firm size after a point and with analyst coverage. Furthermore, the analyst coverage effect is stronger for stocks that are past losers than for stocks that are past winners. For REITs we find that momentum increases with firm size, but it should be recognized that all REITs in the sample are small caps with the largest still only $\$ 1$ billion in size.

Another measure that may capture speed of information dissemination is the degree of insider ownership. On the one hand, pricing errors in stocks largely held and frequently traded by insiders are likely to be small. Any mispricing is likely to be corrected quickly. On the other hand, the speed of mean reversion may be lessened if insiders are restricted from trading on their information. For example, Huddart, Ke and Shi (2006) find that insiders refrain from executing profitable trades before quarterly earnings announcements and sell (buy) after unexpectedly high (low) earnings are announced. In our sample, inside ownership has an inconsistent effect on momentum that varies with specification.

CTW (2003) test the slow information diffusion hypothesis of HS against the investor overconfidence hypothesis of Daniel, Hirshleifer and Subrahmanyam (1998) in the REIT market. They divide their sample into two periods: pre- and post-1990. They only find momentum and reversal in the post-1990 period and argue that this supports the overconfidence theory because information diffusion in the second period was higher than in the first. However, Hung and Glascock (2005) attribute the higher momentum portfolio returns in the latter period to a 1992 change in legislation on REITs that resulted in higher dividend/price ratios. Johnson (2002) showed that momentum portfolios differ in dividend growth rates. Our data are focused on the early period only, where we do find evidence of both reversion and momentum. Our interpretation of the results is quite different.

The existence of transaction costs may prevent prices from reverting if the costs are large enough relative to the mispricing. Lesmond, Schill and Zhou (2004) show that stocks that generate persistent momentum returns are also those with high transaction costs. This result can arise when metrics for fundamental value are not available and are excluded. The measured momentum may actually be 
a reversion to new fundamentals as described above. High transaction costs can slow adjustment and may increase persistence.

Lee and Swaminathan (2000) form 30 portfolios based on past returns and volume using data from all firms listed on the New York Stock Exchange and the American Stock Exchange from 1965 to 1995 . They find that eventually the momentum effect reported by Jegadeesh and Titman (1993) reverses. Furthermore, this reversal is predictable using past volume data. In their sample, the prices of high (low) volume stocks that have performed well (poorly) tend to mean revert more quickly (slowly). Inasmuch as volume is a proxy for transaction costs, this is consistent with HS (1999). By contrast, we are unable to find any affect for dollar volume, the proxy for transaction costs in our sample.

\section{Valuation Precision}

Because we are interested in momentum and mean reversion with respect to the fundamental value, variables related to the ease of valuation are of interest. Mispricing is likely to be more significant in complex firms that are difficult to evaluate than in more focused firms. We use a Herfindahl index as a measure of focus.

The NAV of more highly leveraged firms may be less precisely measured even if debt is easier to value than equity. For example, consider the case where the value of liabilities is known but the assets are measured imprecisely. In this situation, the uncertainty about the fundamental or NAV of the equity will be magnified in percentage terms for more levered firms.

In addition, highly levered firms face possible bankruptcy costs that are difficult to measure (Andrade and Kaplan 1998). As debt increases, bankruptcy becomes more likely. Additionally, market values of debt are also difficult to estimate. On the other hand, if firms have to go to the debt market often, more information may actually be available about the firm and mean reversion may occur more quickly.

To summarize this section, in asset markets efficiency arises from the actions and trading of rational information gatherers. The interaction of boundedly rational traders can result in predictable momentum and reversion in prices. Mean reversion to fundamental value proceeds slowly as information about fundamentals is disseminated to information traders. Momentum in prices arises when price traders, who process only past price movements, identify that prices are trending to a new fundamental value.

These two types of traders are both information producers who evaluate the price impact, the precision and the associated transaction costs before trading on their 
information. High-impact, low-cost information events and firms should attract more information producers and result in faster convergence to equilibrium. The price path, however, may be characterized by overshooting when price traders add sufficient momentum to the dynamics.

In equilibrium, with free entry of information producers, the marginal producer will break even; but intra-marginal (low-cost) producers may earn abnormal returns. More lucrative events and/or securities will attract more information producers who can precipitate faster price adjustments.

\section{Empirical Estimates}

A number of variables are available in the data set that relate to the production of information.

- Log of Size (i.e., market capitalization)_Larger firms tend to be more actively traded and more widely followed by analysts. With better information and lower transaction costs, larger firms should attract more information producers. Adjustment to new information should evolve at a faster pace.

- Log of Dollar volume-As with size, more actively traded firms, that is, more liquid firms, will have lower effective trading costs.

- Debt to Asset Ratio-The ratio of debt to assets measures the degree of financial leverage for the REIT. We expect that information will have more impact on more highly levered firms. Thus, leverage should attract more information producers. Adjustment speeds should be faster for more levered firms.

- Inside Ownership-Insider ownership, as indicated above, can have offsetting impacts. We expect inside owners to have better information but at the same time regulations constrain their trading.

- Herfindahl Focus Index-The focus index measures the extent to which a REIT holds multiple property types (apartment, office, retail and industrial). More focused REITs are easier for investors to evaluate (Capozza and Seguin 1999). Transparency should attract information producers and speed convergence.

\section{Endogenous Dynamic Adjustment}

Estimates for Equation $\left(2^{\prime}\right)$ are presented in Table 3. To control for the effects of market fluctuations, year fixed effects are included in all estimated models. In addition, to control for any omitted characteristics of the firms, individual fixed effects are included in Models 3 and 4 of Table 3 . Included in each model are the lagged return, the lagged deviation from fundamental value and the 


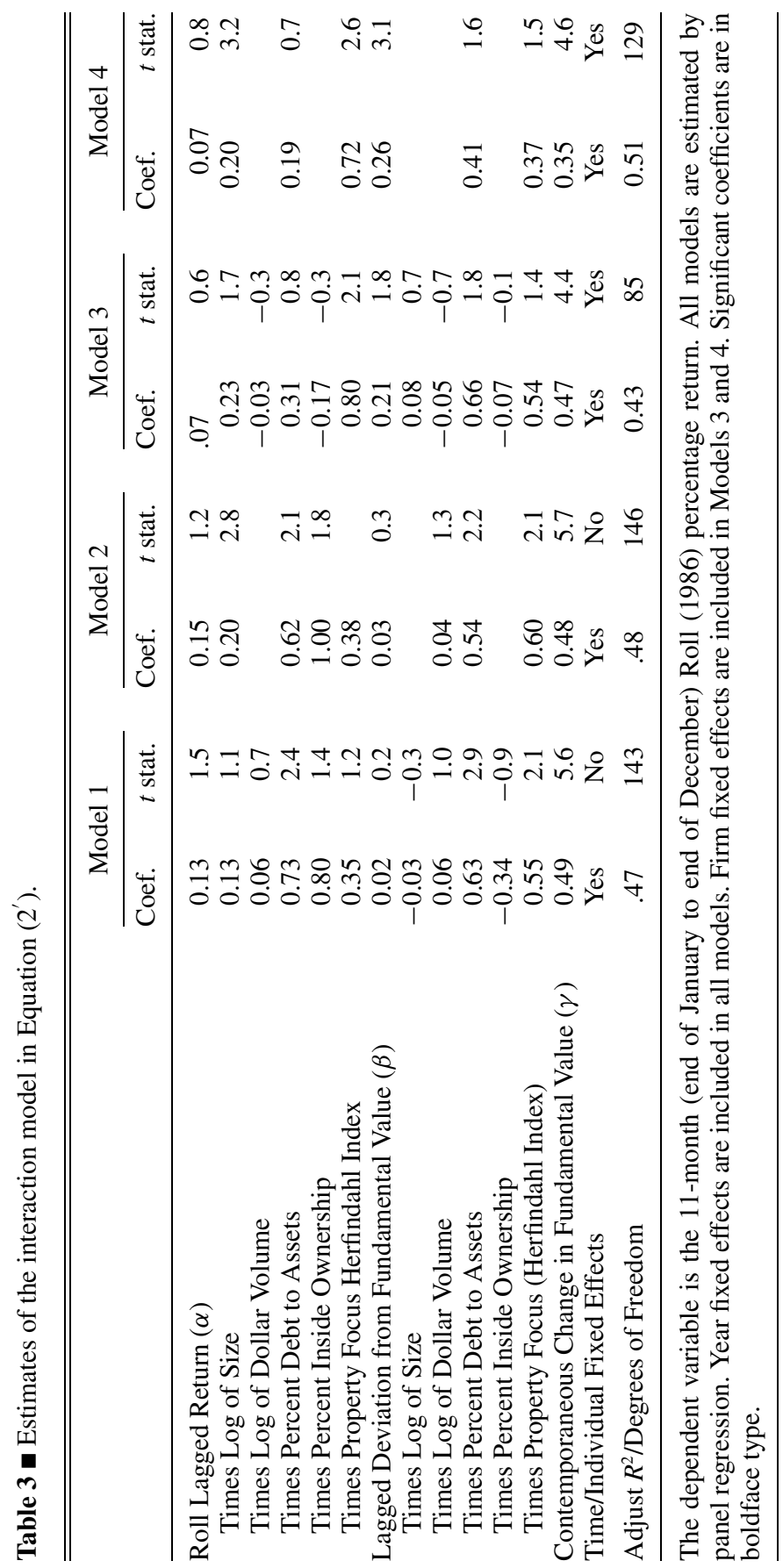


contemporaneous change in fundamental value. In addition, the mean deviation of the five variables above is interacted with the lagged return and the lagged deviation from fundamentals in Models 1-4 of Table 3. The significant coefficients are in boldface.

In the second and fourth model only the most significant interaction terms are included in the regression. To simplify the discussion we concentrate on Model 4 in Table 3. The other models can be viewed as robustness tests. As such we do note that there is some variation in the results depending on the specification. However, there is reliable sign consistency among significant coefficients.

Momentum-The momentum coefficient in Model 4 is $7 \%$, which means that this year's price change is $7 \%$ of last year's. However, the coefficient is not significant. Among the variables interacted with the lagged return, Size, Debt to Assets and Property Focus have positive effects on momentum. Size and Property Focus are significant. The coefficient on size implies that doubling the size of a REIT relative to the average REIT increases the momentum (i.e., autocorrelation) by 0.2 . Price traders have a strong preference for larger REITs. It should be recognized that even the largest REIT in this time period was still quite small with a market capitalization under $\$ 1$ billion.

Price traders are also attracted to focused and levered firms in this sample, consistent with the hypothesis that information producers enter when information is more precise and has more impact. The coefficient on Debt to Assets, however, is not significant in Model 4, although it is in Models 1 and 2.

Mean Reversion-In Model 4 the speed of reversion is $26 \%$ per year, that is, $26 \%$ of the difference between fundamental value and stock price is removed each year. Among the variables interacted with the lagged deviation from NAV, Debt to Assets and Property Focus both have positive effects on the speed of reversion, although Property Focus is not always significant. The higher impact of information for firms with high debt-to-asset ratios attracts information trading as well as price trading. The coefficient on Debt to Assets implies that a fully levered firm (Debt to Assets of 1) will mean revert at nearly three times the rate of an unlevered firm.

\section{How Do the Estimates Relate to the Dynamics Defined by the Difference Equations?}

The implication of Model 4 in Table 3 is that for each time period and for each REIT the dynamics will vary depending on the realizations of the exogenous variables. What do the fitted values for the usable observations tell us about the possible dynamics? 
Figure 3 a Parameter realizations.

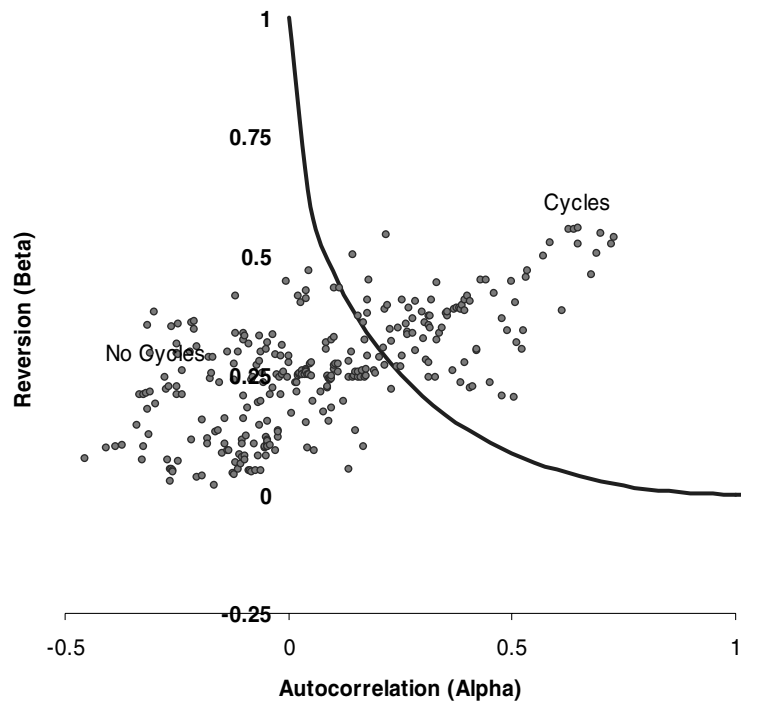

This figure superimposes the fitted values (Table 3, Model 4) for the serial correlation and mean reversion parameters for each of the REIT observations onto the parameter space plot (Figure 1). The mean values for correlation and reversion, 0.07 and 0.26, respectively, lie solidly inside Region I, the convergent, not the oscillation region. However, the fitted values span both the cycle (Region III, convergent oscillations) and no cycle (Region I, convergent no oscillation) regions. Unlike the housing market estimates in CHM (2004), none of the observations have correlations exceeding one, which would put them in the divergent (or bubble) range.

Figure 3 summarizes the results. The figure plots the autocorrelation and mean reversion coefficients for each REIT in each year and is superimposed on Figure 1. Several items are worth noting. First, the realizations are spread over two of the four regions defined earlier and encompass both damped and oscillatory behavior, that is, both underreaction and overreaction.

Second, $71 \%$ of the realizations lie in the damped noncyclical region (I) (see Table 4). Therefore, we can expect damped noncyclical dynamics (underreaction) to be the most common reaction to price shocks. Another $29 \%$ fall into Region III, the convergent oscillation or overreaction region. There are no realizations with an $\alpha$ greater than one, which is necessary for divergent or bubble dynamics.

The typical dynamic pattern when the parameters are set to their average fitted values from Table 3, Model 4 ( $\alpha=0.07, \beta=0.26, \gamma=0.35)$ is depicted in Figure 4 . The pattern is convergent and nonoscillatory. Prices rise substantially in the year of the shock and then slowly converge to the new fundamental value. 
Table 4 a Distribution of fitted parameters for correlation and reversion.

\begin{tabular}{lr}
\hline \hline Region & Percent \\
\hline Region I, Convergent, No Oscillation & 71 \\
Subregion IA, Convergent Alternation & 45 \\
Region II, Divergent, No Oscillation & 0 \\
Region III, Convergent Oscillation & 29 \\
Region IV, Divergent Oscillation & 0 \\
Total & 100 \\
\hline
\end{tabular}

This table lists the percentage of fitted observations in each of the regions defined in Figure 1.

Figure 4 a Dynamic behavior at the sample means.

$$
\text { Alpha }=0.07, \text { Beta }=0.26
$$

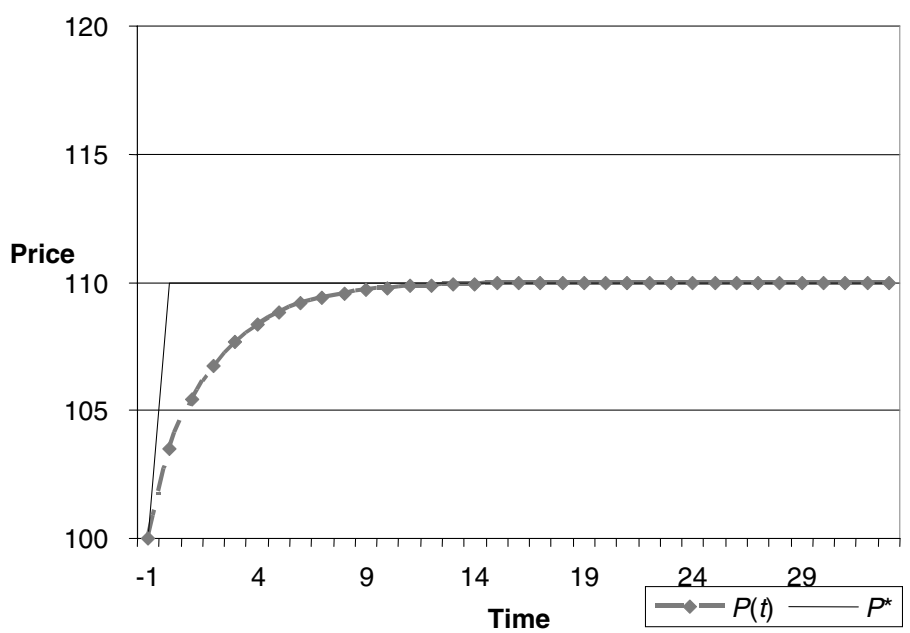

This figure illustrates the dynamic behavior for values of the parameters at the sample estimates in Table 3, Model 4. The pattern is convergent without oscillations at these estimates. Prices converge to the new equilibrium after the shock to the equilibrium value, $P^{*}$, at time 1 . The parameter values used to generate the graph are $\alpha=0.07, \beta=$ 0.26 and $\gamma=0.35$.

To illustrate the range of dynamics arising from the estimates, Figure 5 plots the time series patterns arising when the correlation and reversion parameters are large, based on the realizations from Model 4 in Table $3(\alpha=0.73, \beta=$ $0.54, \gamma=0.35)$. With these values, the time series pattern is still convergent but with persistent oscillations. 
Figure 5 a Dynamic behavior for large $\alpha$ and $\beta$.

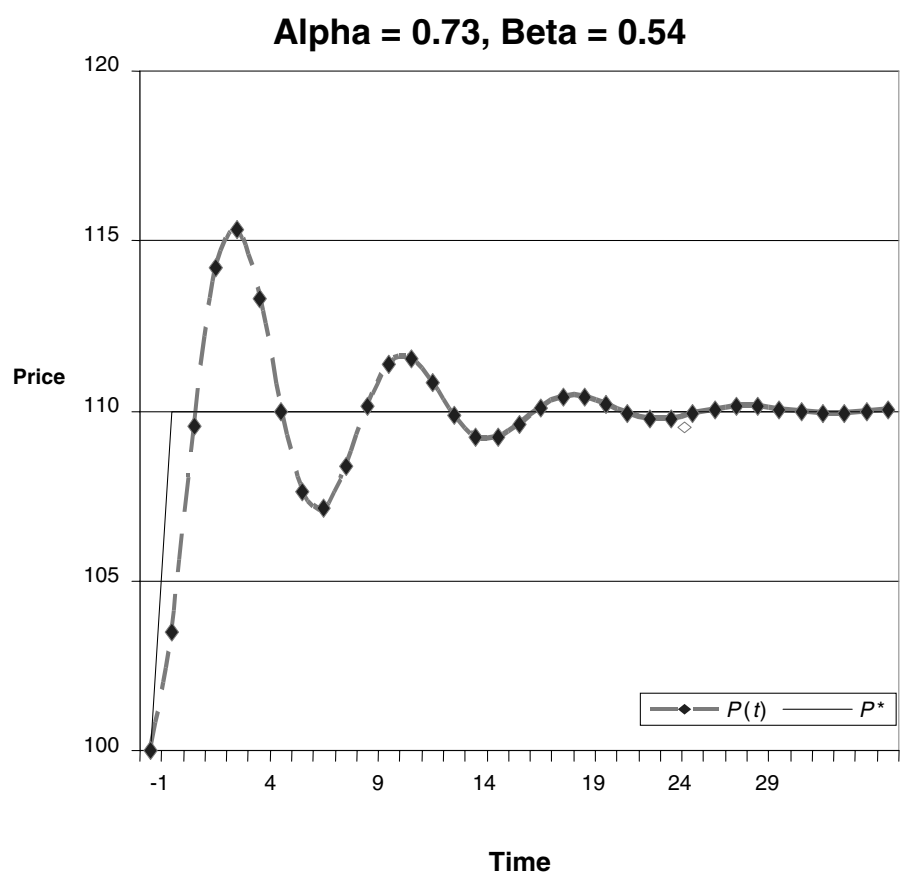

This figure illustrates the dynamic behavior for large realizations of the parameters in Table 3, Model 4. The parameters values are $\alpha=0.73, \beta=0.54$ and $\gamma=0.35$. The graph illustrates the range of dynamics encompassed by the estimates.

\section{Conclusion}

In a world where information is costly to acquire, the structure of the investment industry that supplies and trades on the information can have an impact on the predictability of security prices. Our stylized investment industry is one where fundamental value changes exogenously. The investment industry produces information about the changing fundamental values and trades toward efficient prices. Information is produced using scarce resources, including labor or talent and capital. With fixed costs and free entry into the industry, equilibrium arises when entry of new firms reduces the profits of the marginal firm to normal but intra-marginal producers may still earn abnormal profits.

The interaction of boundedly rational information and momentum traders results in both momentum and mean reversion. Empirically, estimates of reversion require a metric for fundamental value, which is typically not available. In the absence of a metric for reversion, we have argued that estimates of momentum are biased upward. Metrics for fundamental value are available for REITs, the laboratory for our empirical estimates. 
In this stylized world:

- The value of information is the net payoff from trading on the information;

- Information is less costly to acquire for some securities, especially large firms and widely followed firms;

- Net revenue from information is higher for more levered firms and more liquid firms;

- Private information is more valuable than public information so that corporate insiders have an information advantage;

- Barriers to entry increase the value of information, for example, for market makers and specialists.

We exploit the power of the CL $(1995,1996)$ REIT data, which includes estimates of net asset values for 75 REITs calculated from the value of the underlying properties. We use the net asset values as a metric for fundamental value because arbitrage is possible between properties and REITs. Following the framework in CHM (2004) we estimate the momentum and reversion parameters for REITs and compare them to earlier estimates for the housing markets. Like the housing market estimates, REITs also exhibit significant mean reversion. However, unlike the housing estimates, there is little evidence of momentum during the sample period. We note that momentum estimates for housing are biased upward because of the implicit averaging of the dependent variable for housing returns.

We then interact the estimates of the momentum and reversion parameters with REIT size, dollar trading volume, leverage, inside ownership and property focus. We find that momentum is stronger for larger, more focused and more levered REITs. Reversion is faster for more levered and more focused REITs. These results are consistent with the hypothesis that predictability of REIT prices during this period arose from the production of costly information by traders studying both fundamentals (information traders) and price history (price traders). Prices are more predictable when REITs are larger, more levered and more transparent.

We view our result as preliminary because much data collection and research will be needed before we can fully understand how the structure of the investment industry and its diverse participants interact to create the observed predictability in equilibrium. In particular, the results in this research are from a sample of REITs over an 8-year time span. Nevertheless, these results do provide important evidence on equilibrium predictability in financial markets. 
The helpful comments of the reviewers, the discussants, Jim Follain and Robert Novy-Marx and the participants in seminars are gratefully acknowledged. The usual disclaimer applies.

\section{References}

Andrade, G. and S. Kaplan. 1998. How Costly Is Financial (Not Economic) Distress? Evidence from Highly Leveraged Transactions that Became Distressed. The Journal of Finance 53: 1443-1494.

Barberis, N. and M. Huang. 2001. Mental Accounting, Loss Aversion, and Individual Stock Returns. The Journal of Finance 54: 1247-1292.

Barberis, N., A. Shleifer and R. Vishny. 1998. A Model of Investor Sentiment. Journal of Financial Economics 49: 307-343.

Benveniste, L., D.R. Capozza and P.J. Seguin. 2001. The Value of Liquidity. Real Estate Economics 29: 633-660.

Berk, J.B., R.C. Green and V. Naik. 1999. Optimal Investment, Growth Options, and Security Return. The Journal of Finance 44: 1553-1608.

Bern, D.J. 1965. An Experimental Analysis of Self-Persuasion. Journal of Experimental Social Psychology 1: 199-218.

Bhasin, V., R. Cole and J. Kiely. 1997. Changes in REIT Liquidity 1990-1994: Evidence From Intra-Day Transactions. Real Estate Economics 25: 615-630.

Bradley, M.J., D.R. Capozza and P.J. Seguin. 1998. Dividend Policy and Cash Flow Uncertainty. Real Estate Economics 26: 555-580.

Brunnermeier, M.K. 2001. Asset Pricing under Asymmetric Information. Oxford, UK: Oxford University Press.

Brunnermeier, M.K. and L.H. Pedersen. 2006. Market Liquidity and Funding Liquidity. Working paper. Princeton University.

Capozza, D.R., P. Hendershott and C. Mack. 2004. An Anatomy of Price Dynamics in Illiquid Markets: Analysis and Evidence from Local Housing Markets. Real Estate Economics 32: 1-32.

Capozza, D.R. and S. Lee. 1995. Property Type, Size and REIT Value. Journal of Real Estate Research 10: 363-379.

. 1996. Portfolio Characteristics and Net Asset Values in REITs. Canadian Journal of Economics 29(1): S520-526.

Capozza, D.R. and P.J. Seguin. 1998. Managerial Style and Firm Value. Real Estate Economics 26: 131-150.

- 1999. Focus, Transparency and Value. Real Estate Economics 27: 587-620.

Capozza, D.R. and P.J. Seguin. 2000. Debt, Agency and Management Contracts in REITs: The External Advisor Puzzle. The Journal of Real Estate Finance and Economics 20: 91-116.

. 2001a. Debt without Taxes: Capital Structure at REITs. Real Estate Finance 17: $38-46$.

- 2001b. Why Focus Matters. Real Estate Finance 17(4): 7-15.

Chui, A.C.W., S. Titman and K.C.J. Wei. 2003. The Cross-Section of Expected REIT Returns. Real Estate Economics 31: 451-479.

Clapp, J., W. Dolde and D. Tirtiroglu. 1995. Imperfect Information and Investor Inferences from Housing Price Dynamics. Real Estate Economics 23: 239-269.

Clayton, J. and G. MacKinnon. 2000. Measuring and Explaining Changes in REIT Liquidity: Moving Beyond the Bid-Ask Spread. Real Estate Economics 28: 89-115.

Conrad, J. and G. Kaul. 1998. An Anatomy of Trading Strategies. Review of Financial Studies 11: 489-519. 
Daniel, K., D. Hirshleifer and A. Subrahmanyam. 1998. Investor Psychology and Security Market Under- and Overreactions. The Journal of Finance 53: 1839-1886.

De Bondt, W.F.M. and R.H. Thaler. 1985. Does the Stock Market Overreact? The Journal of Finance 40: 793-808.

Durnev, A., R. Morck, B. Yeung and P. Zarowin. 2003. Does Greater Firm-Specific Return Variation Mean More Or Less Informed Pricing? Journal of Accounting Research 41: 797-836.

Heaton, J. and A. Brav. 2002. Competing Theories of Financial Anomalies. Review of Financial Studies 15: 575-606.

Hong, H. and J. Stein. 1999. A Unified Theory of Underreaction, Momentum Trading and Overreaction in Asset Markets. The Journal of Finance 54: 2143-2184.

Hong, H., T. Lim and J. Stein. 2000. Bad News Travels Slowly: Size, Analyst Coverage and the Profitability of Momentum Strategies. The Journal of Finance 55: 265-295.

Huddart, S.J., B. Ke and C. Shi. 2006. Jeopardy, Non-Public Information, and Insider Trading Around SEC 10-K and 10-Q Filings. Available at SSRN: http://ssrn.com/ abstract $=756124$ or DOI: $10.2139 /$ ssrn. 756124

Hung, S.-Y.K. and J.L. Glascock. 2005. Momentum Profitability and Market Trend: Evidence from REITs. Available at SSRN: http://papers.ssrn.com/ sol3/papers.cfm?abstract_id=872604

Jegadeesh, N. 1990. Evidence of Predictable Behavior of Security Returns. The Journal of Finance 25: 881-898.

Jegadeesh, N. and S. Titman. 1993. Returns to Buying Winners and Selling Losers: Implications for Stock Market Efficiency. The Journal of Finance 48: 65-91.

Jegadeesh, N. and S. Titman. 1995. Short-Horizon Return Reversals and the Bid-Ask Spread. Journal of Financial Intermediation 4: 116-132.

Johnson, T.C. 2002. Rational Momentum Effects. The Journal of Finance 57: 585-608.

Kim, J.W., D.J. Leatham and D.A. Bessler. 2006. Modeling REITs' Dynamics Under Structural Change with Unknown Break Points. Mimeo. Texas A\&M University.

Kyle, A. 1985. Continuous Auctions and Insider Trading. Econometrica 53: 13151335.

Lee, C. and B. Swaminathan. 2000. Price Momentum and Trading Volume. The Journal of Finance 55: 2017-2069.

Lesmond, D., M. Schill and C. Zhou. 2004. The Illusory Nature of Momentum Profits. Journal of Financial Economics 71: 349-380.

Lo, A. and C. MacKinlay. 1990. When Are Contrarian Profits Due to Stock Market Overreaction? Review of Financial Studies 3: 175-205.

Odean, T. 1998. Volume, Volatility, Price and Profit When all Traders are Above Average. The Journal of Finance 53: 1887-1934.

Petersen, M. and D. Fialkowski. 1994. Posted Versus Effective Spreads: Good Prices or Bad Quotes? Journal of Financial Economics 35: 269-292.

Pulliam, S. 2006. The Hedge Fund King is Getting Nervous. The Wall Street Journal, September 16, A1.

Quan D. and J. Quigley. 1991. Price Formation and the Appraisal Function in Real Estate Markets. The Journal of Real Estate Finance and Economics 4: 127-146.

Roll, R. 1984. A Simple Implicit Measure of the Effective Bid-Ask Spread in an Efficient Market. The Journal of Finance 39: 1127-1139.

Tversky, A. and D. Kahneman. 1974. Judgement under Uncertainty: Heuristics and Biases. Science 185: 1124-1131.

Working, H. 1960. Note on the Correlation of First Differences of Averages in a Random Chain. Econometrica 28: 916-918. 